\title{
Comparative study of fatty acid and sterol profiles for the investigation of potential milk fat adulteration
}

\author{
M. A. Nurseitova, ${ }^{1}$ F. B. Amutova, ${ }^{1,2 *}$ A. A. Zhakupbekova, ${ }^{1,2}$ A. S. Omarova, ${ }^{1,2}$ A. B. Kondybayev, ${ }^{1,2}$ \\ G. A. Bayandy, ${ }^{1}$ N. N. Akhmetsadykov, ${ }^{1,3}$ B. Faye, ${ }^{4}$ and G. S. Konuspayeva ${ }^{1,2}$ \\ ${ }^{4}$ UMR SELMET, CIRAD-ES, Campus International de Baillarguet, Montpellier, France 34098
}

\section{ABSTRACT}

Milk fat adulteration is a common issue in Central Asia. To assess the current situation in the commercial milk market, 17 milk samples were checked for fatty acid (FA) and sterol profiles to detect potential adulteration using multivariate analysis. Analysis of FA and sterols was performed using gas chromatography with flame ionization detection and gas chromatography with mass-spectrometric detection, respectively. Cluster analysis of FA profiles revealed 3 types of milk samples: (1) samples containing a higher proportion of short-chain FA, (2) samples containing a higher proportion of long-chain FA, and (3) samples with significant amounts of $\mathrm{C} 18 \mathrm{FA}$. Analysis of sterols showed that samples included (1) milk fat containing 100\% cholesterol, sometimes with traces of phytosterols, (2) milk fat with high proportions of $\beta$-sitosterol and campesterol, and (3) milk fat containing high proportions of brassicasterol. We found significant relationships between FA profiles and sterol profiles. The profiles were compared with vegetable oil patterns reported in the literature. More than $50 \%$ of the samples appeared to be counterfeited. We conclude that identification of adulteration in milk can be based solely on determination of sterol patterns.

Key words: milk adulteration, milk fat, fatty acid profile, sterols

\section{INTRODUCTION}

Since the EurAsian Economic Union (EAEU) agreement was signed in 2015, milk products exported from

Received August 29, 2018.

Accepted April 23, 2019.

*Corresponding author: antigen.chem@gmail.com
EAEU member countries (Belarus, Russia, the Kyrgyz Republic, and Armenia) have been piling up on the store shelves of Kazakhstan, which has the highest import figures for milk products among EAEU countries. Moreover, recently Russia and Indonesia signed an agreement to import low-cost palm oil to the EAEU (Tochieva, 2011), posing an increased risk of use of this vegetable fat as a substitute for milk fat in normalized or reconstituted milk, as has been revealed in the national press (Kazinform, 2016). Milk adulteration is considered a top-priority problem for 2 main reasons: (1) It could pose risks for human health, as confirmed in reports regarding the melamine crisis in China (Guan and Deng, 2016); (2) It is a consumer fraud. Indeed, even if there is no risk to consumers, the substitution of a specific food component with another one (food product counterfeiting) can lead to huge scandals, as was the case with the horse meat found in "beef meat lasagna" in France (Iwobi et al., 2017). In addition to the fact that substitution of milk fat with vegetable oil is considered counterfeiting, consumption of certain forms of palm oil has been associated with health risks to consumers (Falade et al., 2015; Mba et al., 2015).

In Kazakhstan, fatty acid (FA) composition has been studied in the milk of different dairy species, such as camels (Konuspayeva et al., 2008; Narmuratova et al., 2006), mares (Tultabayeva et al., 2015), and cows (Tultabayeva et al., 2013). These studies, however, dealt with raw natural milk, focusing on physiological aspects of milk components only, and did not include potentially adulterated milk. Analysis of FA profiles represents the primary method used in Kazakhstan (Kalamkarova et al., 2013) and other countries (Perotti et al., 2005; Ntakatsane et al., 2013) to determine milk fat adulteration by substitution with vegetable oil. However, determination of sterol profiles could also be a convenient method to identify adulterated milk fat (Nascimento et al., 2017). Indeed, only cholesterol is normally found in the fat fraction of milk (Chmilenko 
et al., 2011), and the presence of phytosterols should indicate milk fat adulteration (Abd El-Aziz et al., 2013; Marrikar et al., 2016).

Most published studies considering the problem of milk adulteration have been focused on experimental adulteration, aimed at assessing the sensitivity of analytical methods in detecting the presence of vegetable oils (Chmilenko et al., 2011; Abd El-Aziz et al., 2013; Ntakatsane et al., 2013). However, to the best of our knowledge, no study has yet been published that compares the detection of phytosterols with the FA profile, as methods to determine the fact of adulteration in commercial milk with various fat content levels. In Poland, a similar comparison has been carried out, but this was based on studying commercial butter (Derewiaka et al., 2011). Moreover, the phytosterol method for determination of milk purity is not yet officially included in the list of approved government standards (GOST) among EAEU countries, despite its obvious advantages in higher specificity, shorter duration of analysis, and lower cost.

Thus, our main objective is to show the differences and advantages of 2 methods of detection, by studying potentially adulterated commercial milk for the first time in the history of Kazakhstan. The specific objectives of the present paper include the following: (1) to determine FA and sterol profiles of all commercial milk samples (full-fat or semi-skimmed) available on the market in Kazakhstan, (2) to identify potential adulteration in these samples by using multivariate analysis, and (3) to assess the convenience of using these methods, by comparing samples with different vegetable oil compositions available in the literature.

\section{MATERIALS AND METHODS}

\section{Sampling Procedure}

We purchased 17 commercial milk packages of different trademarks at the Almaty (Kazakhstan) market. Countries of origin of these milk samples included Russia (1), Belarus (1), the Kyrgyz Republic (1), and different regions of Kazakhstan (14 samples). They represented the whole range of commercial trademarks available on the local market. The characteristics of the milk samples are reported in Table 1. The analyses used the original milk without any modification (such as deep-freezing) and within its shelf-life period.

\section{Laboratory Analyses}

Each milk sample was initially analyzed for gross composition (fat, protein, lactose, density, nonfat solids, and water content) using a milk analyzer (Lactan 1-4, 2012, Sibagropribor, Krasnoobsk, Russia). Before analysis, the milk analyzer was calibrated by the National Center of Expertise and Certification (Almaty, Republic of Kazakhstan). Subsequently, each sample was submitted to 2 types of analysis for FA composition and sterol profile.

\section{Fatty Acid Composition Analysis}

Fatty acid composition was determined using gas chromatography with flame ionization detection (Shimadzu GC2010, Kyoto, Japan), in strict adherence to the procedure described in ISO 12966-2:2017: "Animal

Table 1. Characteristics of 17 milk samples from Almaty (Kazakhstan) market

\begin{tabular}{llcl}
\hline Sample number & Thermal treatment & Fat percentage & Origin (country) \\
\hline 1 & Pasteurized & 2.5 & Kazakhstan \\
2 & Pasteurized & 3.2 & Kyrgyz Republic \\
3 & Pasteurized & 2.5 & Kazakhstan \\
4 & Pasteurized & 3.2 & Kazakhstan \\
5 & Pasteurized & 2.5 & Russia \\
6 & UHT & 2.5 & Kazakhstan \\
7 & Pasteurized & 2.2 & Kazakhstan \\
8 & UHT & 2.5 & Kazakhstan \\
9 & UHT & 2.5 & Kazakhstan \\
10 & UHT & 2.5 & Kazakhstan \\
11 & UHT & 2.5 & Kazakhstan \\
12 & UHT & 2.5 & Kazakhstan \\
13 & UHT & 2.5 & Belarus \\
14 & UHT & 2.5 & Kazakhstan \\
15 & UHT & 2.5 & Kazakhstan \\
16 & Pasteurized & 2.5 & Kazakhstan \\
17 & UHT & 2.5 & Kazakhstan \\
\hline
\end{tabular}


and vegetable fats and oils: Preparation of methyl esters of fatty acids."

To prepare sodium methylate in methanol, $2.70 \pm$ $0.01 \mathrm{~g}$ of sodium methylate powder (product no. 164992, Sigma-Aldrich, St. Louis, MO) was dissolved with 10 $\mathrm{mL}$ of absolute methanol (product no. 34860, SigmaAldrich) in a 25-mL volumetric flask. The solution was stirred, cooled to the ambient temperature, and topped up with absolute methanol to the mark.

To extract milk fat, $1 \mathrm{~L}$ of each milk sample was placed into $50-\mathrm{mL}$ falcon tubes and centrifuged at 9,146 $\times g$ for $15 \mathrm{~min}$ at $-4^{\circ} \mathrm{C}$. The upper fat fraction was placed in a $250-\mathrm{mL}$ beaker, and $150 \mathrm{~mL}$ of n-hexane (product no. 34859, Sigma-Aldrich) was added. This was homogenized on a magnetic stirrer for $5 \mathrm{~min}$ and transferred to a $250-\mathrm{mL}$ round-bottomed flask. The solvent was evaporated $\left(70 \pm 2^{\circ} \mathrm{C}\right)$ to dryness. The remaining fat fraction was used to prepare FAME.

For the preparation of FAME, $0.10 \pm 0.02 \mathrm{~g}$ of milk fat from each brand was weighed in a falcon tube and dissolved in $2 \mathrm{~mL}$ of n-hexane. Next, $0.5 \mathrm{~mL}$ of sodium methylate solution in methanol was added and intensively stirred for $5 \mathrm{~min}$. The reaction mixture was settled for $5 \mathrm{~min}$ and centrifuged at $9,146 \times g$ for 15 $\min$ at $-4^{\circ} \mathrm{C}$. The supernatant was used for GC injection $(1 \mu \mathrm{L})$.

An HP-88 column was used for chromatographic analysis of FAME (part number 112-88A7, Agilent Technologies, Santa Clara, CA), $100 \mathrm{~m} \times 0.250 \mathrm{~mm} \times$ $0.20 \mu \mathrm{m}$. The carrier gas was nitrogen (grade A, UMZ company, Almaty, Kazakhstan), makeup flow $-30 \mathrm{~mL} /$ min. Flow rates of hydrogen were $-30 \mathrm{~mL} / \mathrm{min}$, with air flow $-400 \mathrm{~mL} / \mathrm{min}$. The chromatography parameters used were as follows: $260^{\circ} \mathrm{C}$ for injector temperature, 100:1 for split mode, $104 \mathrm{~mL} / \mathrm{min}$ for total flow, $1 \mathrm{~mL} /$ min for column flow, $250^{\circ} \mathrm{C}$ for detector temperature. The column temperature program started from $140^{\circ} \mathrm{C}$ for $5 \mathrm{~min}$, then increased to $240^{\circ} \mathrm{C}\left(4^{\circ} \mathrm{C} / \mathrm{min}\right)$ for 5 min; temperature was then increased to $250^{\circ} \mathrm{C}\left(2^{\circ} \mathrm{C} /\right.$ $\mathrm{min}$ ) and maintained for $7 \mathrm{~min}$. Total time of analysis was $47 \mathrm{~min}$. The analytical standard used was FAME Mix C4-C24, 100 mg Neat (catalog no. 18919-1AMP,
Sigma-Aldrich). Analysis identified 37 FAME; then the content of analytes was determined by normalizing peak areas (reduction to 100\%; i.e., finding the percentage of each component). Analyses were performed in duplicate after checking the similarity of the results. Data analysis was then performed on the means.

\section{Sterol Analysis}

The concentrated solution of sterol fractions was analyzed using gas chromatography with massspectrometric detection (7890B/5977B, Agilent Technologies). Chromatography was performed using an HP-5MS capillary column $30 \mathrm{~mm}$ long, with inner diameter of $0.25 \mathrm{~mm}$ and film thickness of 0.25 $\mu \mathrm{m}$. The carrier gas (grade-A helium, Tehgas LLC, Orenburg, Russia) was fed at a constant rate of 1.0 $\mathrm{mL} / \mathrm{min}$. The injector temperature was $310^{\circ} \mathrm{C}$ in split mode at 10:1. The temperature of the thermostat was programmed from $115^{\circ} \mathrm{C}$ (held for $1 \mathrm{~min}$ ) to $260^{\circ} \mathrm{C}$, with a heating rate of $13^{\circ} \mathrm{C} / \mathrm{min}$, then raised to $290^{\circ} \mathrm{C}$ at a rate of $5^{\circ} \mathrm{C} / \mathrm{min}$ (held for $6 \mathrm{~min}$ ). The total time of chromatography was $24.15 \mathrm{~min}$. The temperatures of the interface, quadrupole, and source of mass spectrometer detector were $290^{\circ} \mathrm{C}, 150^{\circ} \mathrm{C}$, and $230^{\circ} \mathrm{C}$, respectively. Mass spectrometric detection was carried out in the selected ion monitoring mode (Table 2). The standards of cholesterol (product No. C8667), $\beta$-sitosterol (product No. 43623), brassicasterol (product No. B4636), stigmasterol (product No. S2424), and campesterol (product No. C5157) were purchased from Sigma-Aldrich. The international standard used was 33490-2015, "Detection of vegetable oils and plant-based fat by gas-liquid chromatography with mass-spectrometric detection" (GOST, 2015).

Data processing included determination of retention times and peak areas; processing of spectral information was obtained with the help of the mass spectrometric detector. To decrypt the mass spectra, the 10th-edition Wiley library was used (total number of spectra in the library: over 550,000). For FA, the content of analytes was determined by normalizing peak areas.

Table 2. Analytical characteristics (CAS number, retention time, and SIM) ${ }^{1}$ of analyzed milk sterols

\begin{tabular}{llcc}
\hline Compound & CAS number & $\begin{array}{c}\text { Retention time } \\
(\mathrm{min})\end{array}$ & SIM $(\mathrm{m} / z)$ \\
\hline Cholesterol & $57-88-5$ & 20.281 & 386 \\
Brassicasterol & $474-67-9$ & 20.945 & 398 \\
Campesterol & $474-62-4$ & 21.848 & 400 \\
Stigmasterol & $83-48-7$ & 22.366 & 412 \\
$\beta$-Sitosterol & $83-46-5$ & 23.362 & 414 \\
\hline
\end{tabular}

${ }^{1}$ CAS number is an identifier assigned by the Chemical Abstracts Service. SIM = selected ion monitoring. 


\section{Statistical Analysis}

The objectives of the statistical analysis were as follows: (1) to identify the different FA and sterol patterns in the milk samples, (2) to assess the relationships between the types of FA profiles and the types of sterols profiles, and (3) to analyze the proximity of FA and sterol profiles with vegetable oil profiles available in the literature. The software used for all statistical analyses was Addinsoft (2017, XLSTAT-Base, Paris, France).

To achieve the first objective, the data tables "Fatty acids" (17 samples $\times 37$ acids) and "Sterols" (17 samples $\times 5$ sterols) were analyzed using principal components analysis (PCA), Pearson type (Jolliffe, 2002), followed by ascending hierarchical classification using Euclidian distance and Ward method (Everitt et al., 2001) for identifying homogeneous groups, defined as types of profiles. For the second objective, a class number, issued from classification, was given to each sample, one for FA profiles and one for sterol profiles. A contingency table crossing the 2 classifications (confusion matrix) was implemented, and a chi-squared test was applied to assess the independency between the types of FA profiles and sterol profiles.

In addition, the different profiles were described according to the level of total fat in the samples (low fat $<2.5 \%$; high fat $\geq 2.5 \%$ ) and thermic treatment: pasteurized or ultra-high temperature (UHT). One-way ANOVA was applied to determine the differences between these variables, after checking the normality of distribution. The qualitative variables class fat-1 (low fat), class fat-2 (high fat), typmilk1 (pasteurized), and typmilk2 (UHT) were used as supplementary variables in the PCA.

For the third objective, PCA and ascending hierarchical classification were performed on a table including as variables simplified FA and sterol profiles, and, as individuals, the 17 milk samples plus vegetable oils (rapeseed, soybean, peanut, corn, sunflower, sesame, tea-seed, and palm). As a reference, the composition of one fresh raw milk sample collected by the authors from a local farm was added to the table. Data regarding vegetable oils were collected from the literature $(\mathrm{Li}$ et al., 2011).

\section{RESULTS}

\section{Milk Composition}

The mean values of milk components were $2.44 \% \pm$ 0.31 (range: 2.00 to $3.21 \%$ ) for fat, $2.85 \% \pm 0.24$ (range: 2.23 to $3.23 \%$ ) for protein, and $7.68 \% \pm 0.58$ (range: 5.94 to $8.67 \%$ ) for nonfat solids. Milk sample 11 had the lowest values for all parameters measured $(2.00 \%$ for fat, $2.23 \%$ for protein, and $5.94 \%$ for nonfat solids).

\section{Fatty Acid Profiles}

Patterns of FA profiles appeared slightly different between low-fat $(<2.5 \%)$ and high-fat $(\geq 2.5 \%)$ milk, but no significant difference occurred between pasteurized and UHT milk (Table 3), although there was significant relationship between fat level and thermic treatment, with high-fat milk being significantly more frequent in pasteurized products $\left(\chi^{2}=3.84, P<0.05\right)$. Low-fat milk contained significantly lower levels of short-chain SFA (C4:0, C6:0, C8:0, C10:0, C12:0), but also containing lower levels of long-chain FA: C15:0, C15:1, and C17:0. On the other hand, C21:0 and C22:5n-3 were in lower proportions in high-fat milk.

Despite the large number of variables (37 FA), the 2 first principal components of the PCA were quite predominant, expressing more than $60 \%$ of the total variance, and $75 \%$ of FA contributed significantly to these 2 first principal components. The main factorial plan showed a distinct distribution of the 17 milk samples in 3 groups (Figure 1), confirmed by automatic classification (Figure 2) and structure into 3 types of milk, explaining $85 \%$ of the total variance.

The first group of milk samples (type $1 \mathrm{f}, \mathrm{n}=8$ ) are projected at the right side of the factorial plan (Figure 1 ). These samples contained a higher proportion of short-chain FA and SFA than did the 2 other groups. Butyric (C4:0), caproic (C6:0), caprylic (C8:0), capric (C10:0), undecanoic (C11:0), lauric (c12:0), myristic (C14:0), pentadecanoic (C15:0), palmitic (C16:0), and heptadecanoic (C17:0) were present in significantly higher proportions $(P<0.001)$ in this group of milk samples than in the 2 other groups. In addition, some monosaturated FA were present in significantly $(P<$ 0.001 ) higher proportions than in the other 2 groups: myristoleic (C14:1), cis-10-pentadecenoic (C15:1), and palmitoleic acid (C16:1). Among polyunsaturated acids, only $\alpha$-linoleic acid (C18:3n-3) was present in significantly higher proportion than in other groups. The projection of supplementary variables (class fat and typmilk) showed proximity of high-fat milk (class fat-2) with this group of samples. However, the correspondence was not $100 \%$. Indeed, 2 low-fat milk samples (7 and 13) were found in this group.

The second group of milk samples (type 2f), projected at the left side of the main factorial plan, was characterized by its significantly low values $(P<0.001)$ of palmitic (C16:0) and linoleic acid (C18:2n-6 cis) and its richness in linolelaidic acid (C18:2n-6 trans). For ex- 
Table 3. Fatty acid (FA) composition, expressed as $\%$ of total FA, in 17 commercial milk samples according to level of fat $(<2.5$ or $\geq 2.5 \%)$ and thermic treatment

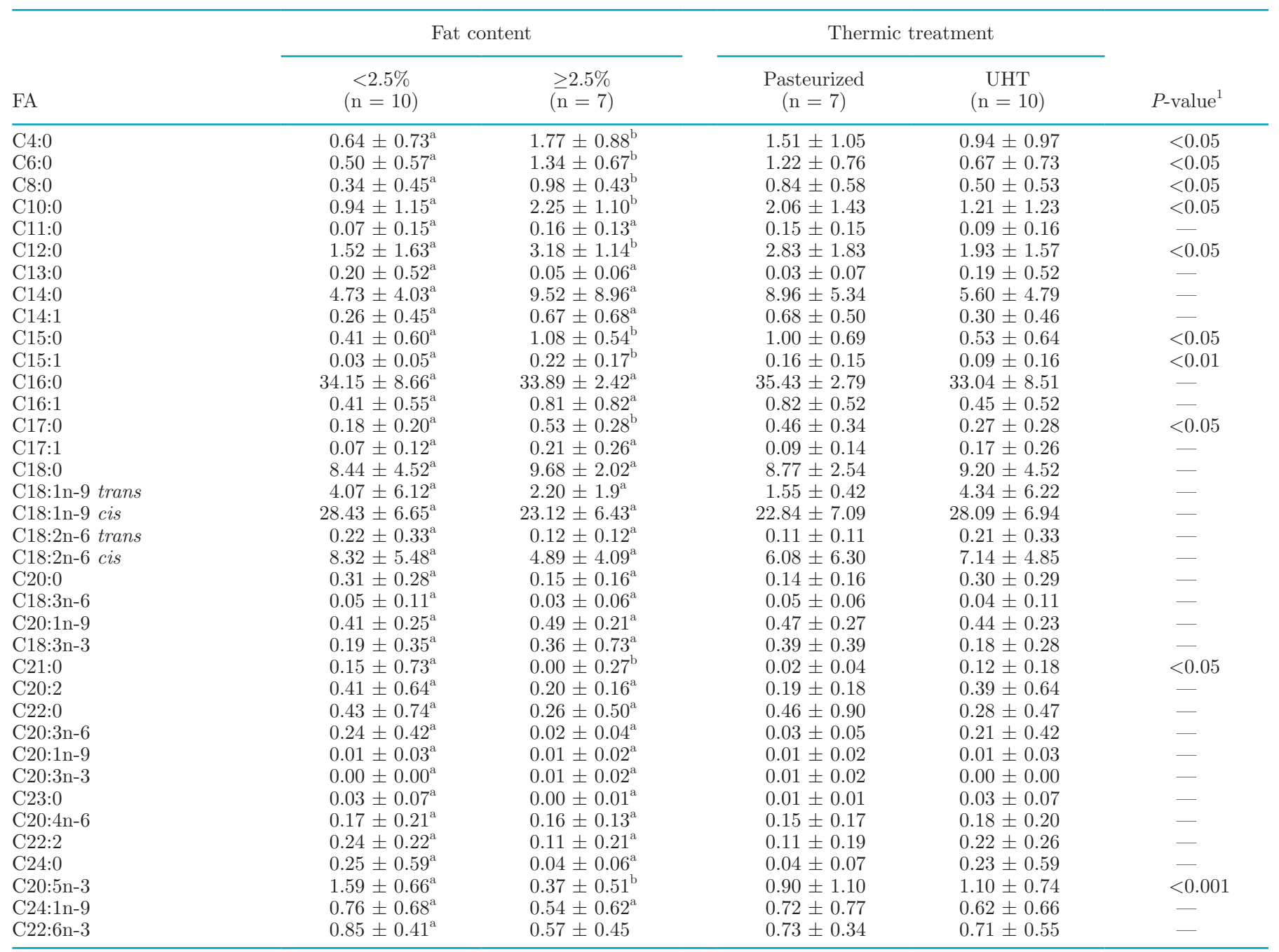

${ }^{\mathrm{a}, \mathrm{b}}$ Different superscripts in rows indicate differences significant to degree specified.

${ }^{1} P$-value is given for fat content only, no difference occurring for thermic treatment.

ample, the proportion of linoleic acid in this group was $2.36 \%$, as opposed to $11.7 \%$ in group 1f (Figure 3 ). The supplementary variable class fat-1 (low-fat milk) was closed to that group of samples. However, 2 samples ( 8 and 17) were also in this second group despite their high fat content $(2.52 \%$ and $2.50 \%$, respectively).

The last group (type 3f) included only one low-fat sample (14), characterized by a higher proportion $(P<0.001)$ of FA with 18 atoms of carbon: stearic (C18:0), elaidic (C18:1n-9 trans), oleic (C18:1n-9 cis), linolelaidic (C18:2n-6 trans), and $\gamma$-linolenic acid (C18: 3n-3). Long-chain SFA were also in significantly higher proportion $(P<0.001)$ in this group compared with the 2 other groups: palmitic (C16:0), stearic (C18:0), arachidic (C20:0), tricosanoic (C23:0), and lignoceric acid (C24:0).
The regrouping by saturation status of FA (SFA, MUFA, or PUFA) confirmed the difference in patterns between the 3 types of milk (Figure 4).

\section{Sterol Profiles}

Cholesterol content was significantly higher in highfat milk, with $99.1 \pm 0.80 \%$, whereas in low-fat milk the content was on average $64.2 \pm 29.5 \%$. However, phytosterols were present to a greater extent in low-fat milk, especially $\beta$-sitosterol, with $23.3 \pm 18.8 \%$ (Table 4). We found no significant difference in the mean sterol profile of pasteurized milk compared with UHT. The PCA showed a clear opposition between cholesterol and all phytosterols, especially campesterol and $\beta$-sistosterol. Stigmasterol and brassicasterol were in 
Biplot (axes F1 and F2 : 60.11\%)

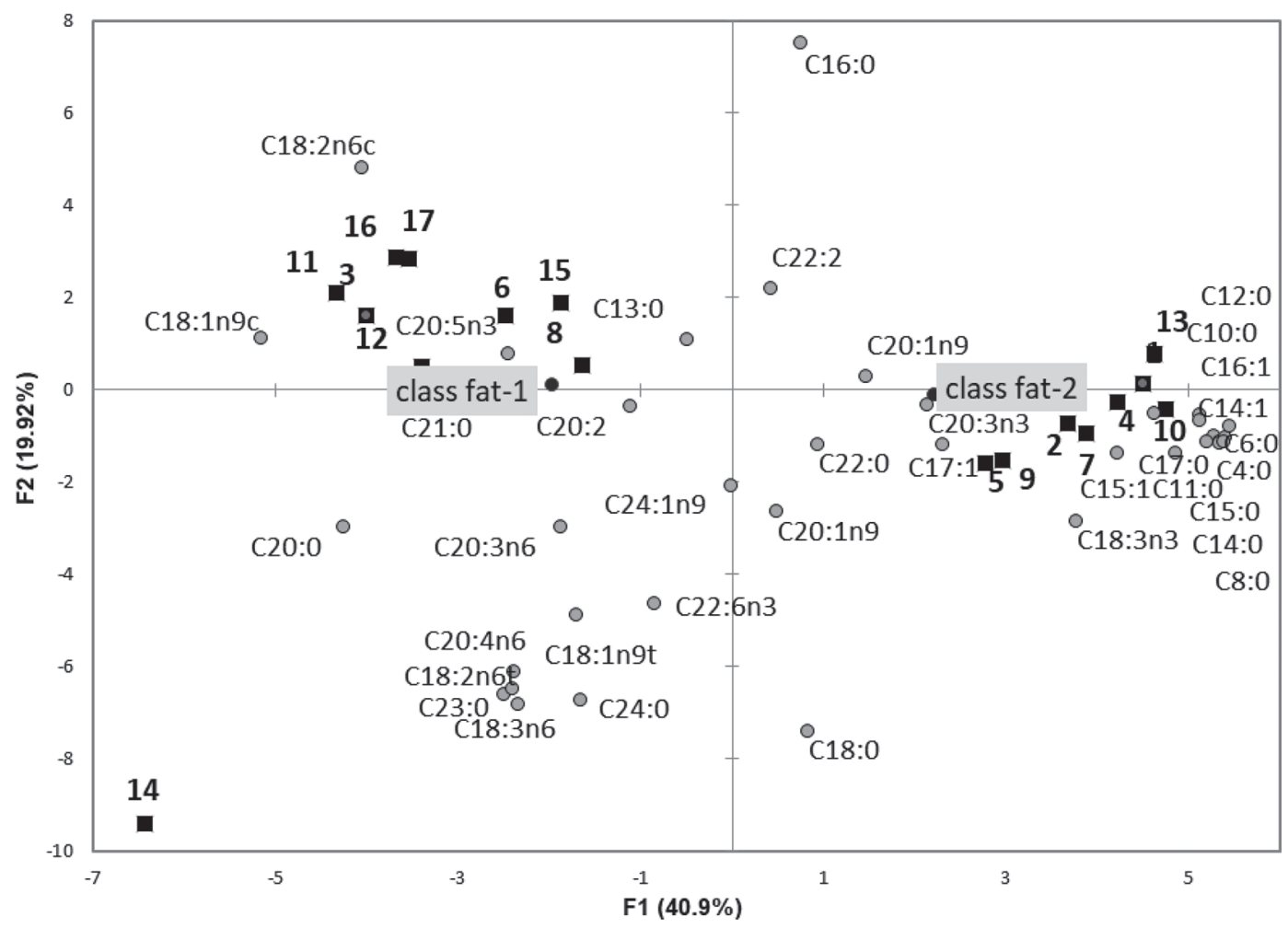

Figure 1. Factorial plan (F1, F2) of the principal components analysis (PCA) applied on data table (17 milk samples $\times \%$ of fatty acids). Numbers correspond to identification of milk samples. The level of total fat was included as a supplementary variable (class fat-1 = low-fat milk; class fat-2 = high-fat milk).

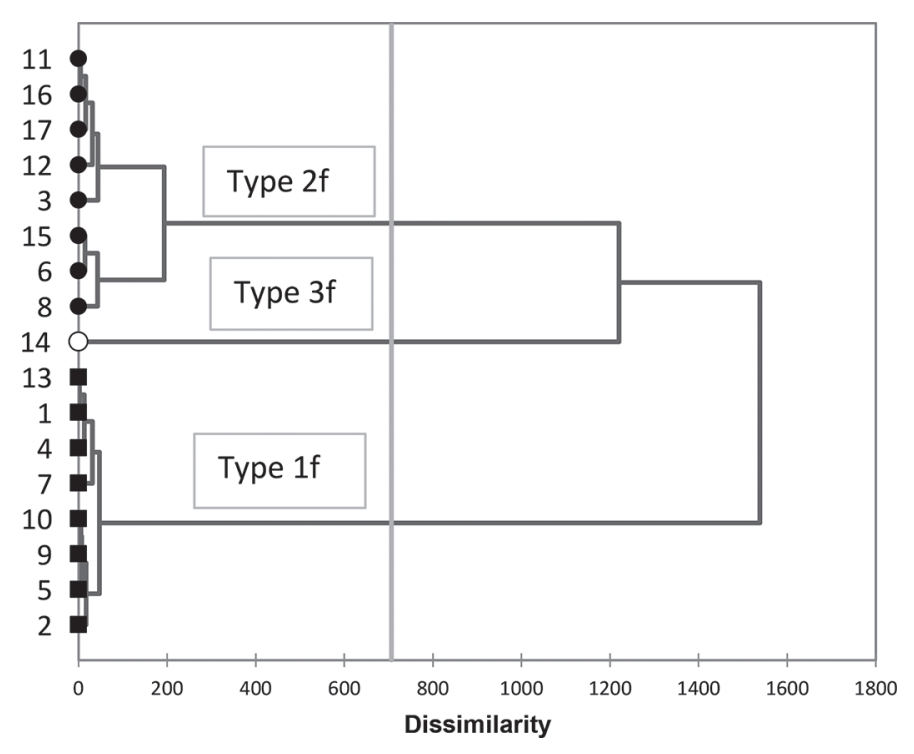

Figure 2. Classification tree and dissimilarity levels of the 3 types of fatty acid profiles (37 fatty acids) of 17 milk samples derived from ascending hierarchical classification. Vertical line indicates the cutting level of the dendrogram. opposition on the second factor of the PCA (Figure 5A). The structure proposed by the main factorial plan (F1, F2) explained $96 \%$ of the variance. Clearly, 2 groups of milk samples were detected. The first, on the right side of the graph, included all samples rich in cholesterol, whereas on the left side the samples contained a significantly $(P<0.05)$ higher proportion of phytosterol. Two samples (3 and 14) seemed different and opposed on the second factor due to their specific abundance in stigmasterol and brassicasterol, respectively. This spatial distribution was confirmed by the cluster analysis showing 3 groups of milk samples according to their sterol pattern (Figure 6).

The first group (type 1s) contained 10 milk samples with high cholesterol content $(99.2 \%)$ and no phytosterol except $\beta$-sistosterol ( $0.8 \%$ on average). The second group (type $2 \mathrm{~s}, \mathrm{n}=5$ ) was low in cholesterol $(68.0 \%)$, but $\beta$-sistosterol $(22.2 \%)$ and stigmasterol $(3.6 \%)$ were in higher proportion here than in other types of sterol profiles. The third group (type $3 \mathrm{~s}$ ) contained samples 3 and 14, characterized by relatively high proportions of campestrine $(6.9 \%)$ and brassicasterol $(0.55 \%)$. 
-Type 1f gType $2 f$ 口Type $3 f$

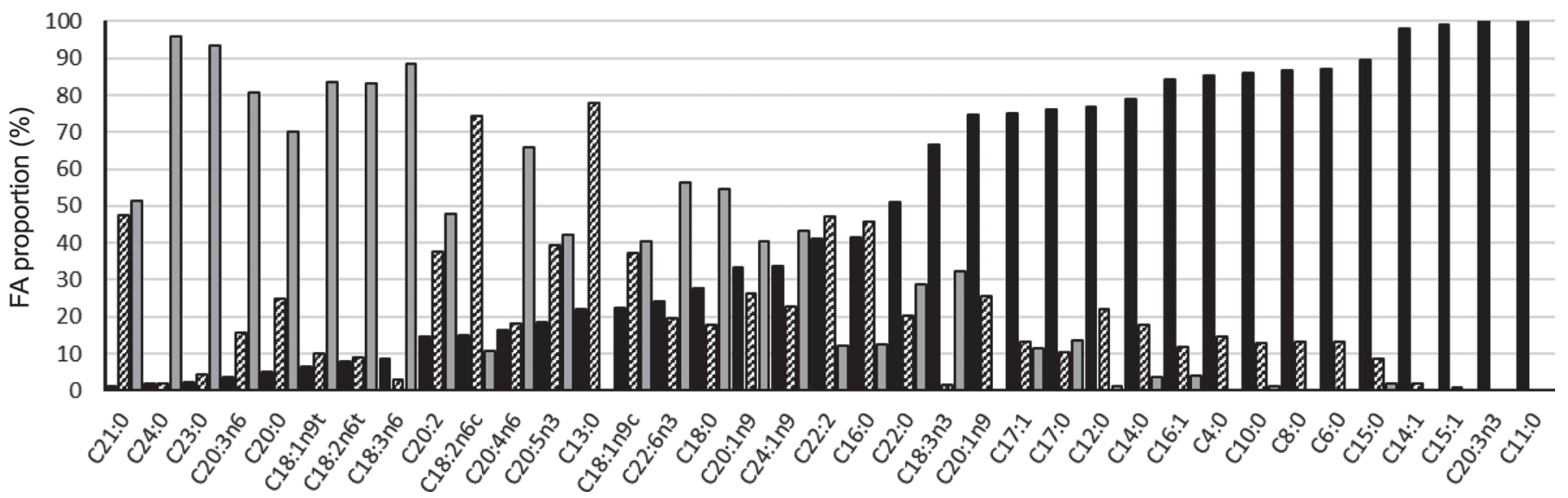

Figure 3. Fatty acid (FA) patterns of the 3 types of milk samples [1f (solid black bars), 2f (diagonally striped bars), and 3f (solid gray bars)] obtained after clustering analysis of their FA composition. For ease of reading, the total percentage for each FA was $100 \%$. Moreover, for better comparison between the patterns, values for type $1 \mathrm{f}$ were sorted by increasing values of each FA (in black). $\mathrm{t}=$ trans; $\mathrm{c}=$ cis.

Contrary to the types of FA profiles, we found no significant relationships between types of sterol profiles and fat level in milk $\left(\chi^{2}=5.99, P=0.084\right)$.

\section{Relationships Between Types of Fatty Acids and Sterol Profiles}

Each milk sample was characterized by one type of FA profile and sterol profile. The chi-squared test applied to the cross-table (contingency table FA $\times$ sterols) was highly significant $\left(\chi^{2}=9.48 ; \mathrm{df}=4 ; P<\right.$ 0.001 ), showing relationships between those 2 patterns. Eight samples of type 1f (high proportion of short-chain FA and SFA) were included in the group 1s (high cholesterol). Five $2 \mathrm{f}$ samples (out of 8) rich in $\mathrm{C} 18 \mathrm{FA}$ were included in the 2 s group (rich in $\beta$-sitosterol and

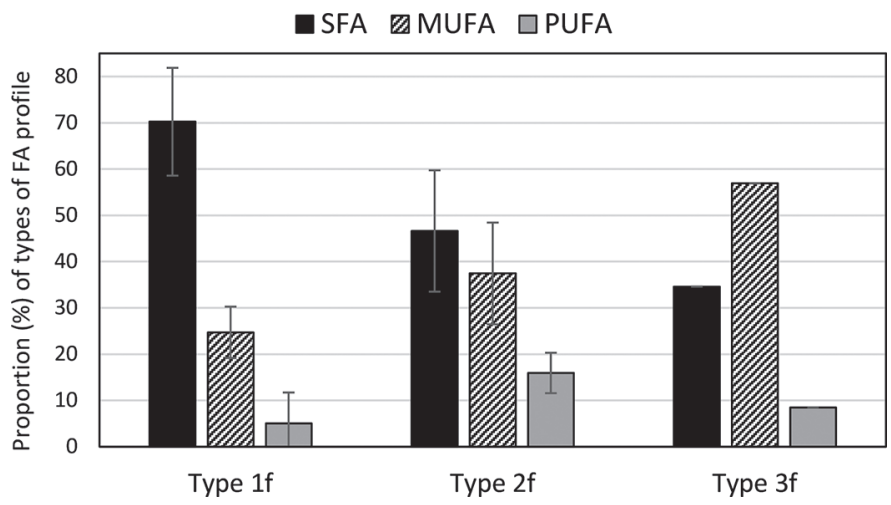

Figure 4. Mean composition of the different types of milk, according to automatic classification. Error bars represent SD. FA = fatty acid. stigmasterol). Sample 14 (type 3f) was characterized by its high proportion of brassicasterol.

\section{Comparison with Vegetable Oil Profiles}

Regarding FA profiles, the main factorial plan (F1, F2) of the PCA showed that the group of milk samples corresponding to type $1 \mathrm{f}$ were at the opposite side from the vegetable oils. However, there was proximity between most of the vegetable oil profiles and the second group of milk samples projected at the left side of the factorial plan (Figure 5B). Sample 14 was projected close to the peanut oil FA composition. This spatial distribution was confirmed by analysis of the sterol profiles, with the second group of milk samples projected at the left side of the main factorial plan of the PCA, close to the vegetable oil profiles. Sample 14, rich in brassicasterol, was close to rapeseed oil, and sample 3 was close to the other vegetable oils (Figure 5C).

\section{DISCUSSION}

The group of milk samples corresponding to the types 1f or 1s could be regarded as unadulterated milk. Their FA profile was consistent with standard milk composition (GOST, 2013) and raw milk analyzed in Kazakhstan (Tultabayeva et al., 2013). Most of these samples were high-fat milk. However, low-fat milk samples were also included in this group. Probably, the addition of fat for normalizing fat content in high-fat samples was achieved with milk fat only, regardless of the final fat level.

The milk samples of type $2 \mathrm{f}$ presented a different FA profile, which could be considered partly altered, 
Table 4. Sterol composition, expressed as \% of total sterols, in 17 commercial milk samples, according to level of fat $(<2.5$ or $\geq 2.5 \%)$ and thermic treatment (Pasteurized or UHT)

\begin{tabular}{lccccc}
\hline Sterol & $\begin{array}{c}\text { Low fat } \\
\mathrm{n}=10\end{array}$ & $\begin{array}{c}\text { High fat } \\
\mathrm{n}=7\end{array}$ & $\begin{array}{c}\text { Pasteurized } \\
\mathrm{n}=7\end{array}$ & $\begin{array}{c}\text { UHT } \\
\mathrm{n}=10\end{array}$ & $P$-value $^{1}$ \\
\hline Cholesterol & $64.2 \pm 29.5^{\mathrm{a}}$ & $99.1 \pm 0.8^{\mathrm{b}}$ & $81.0 \pm 32.6$ & $69.9 \pm 27.9$ & $<0.05$ \\
Brassicasterol & $0.5 \pm 1.6^{\mathrm{a}}$ & $0.0 \pm 0.0^{\mathrm{a}}$ & $0.0 \pm 0.0$ & $0.6 \pm 1.7$ & - \\
Campesterol & $8.3 \pm 9.4^{\mathrm{a}}$ & $0.1 \pm 3.9^{\mathrm{a}}$ & $3.7 \pm 6.8$ & $7.4 \pm 9.9$ & - \\
Stigmasterol & $3.7 \pm 3.7^{\mathrm{a}}$ & $0.0 \pm 0.1^{\mathrm{a}}$ & $2.0 \pm 3.8$ & $3.0 \pm 3.4$ & - \\
$\beta$-Sitosterol & $23.3 \pm 18.8^{\mathrm{a}}$ & $0.8 \pm 0.7^{\mathrm{b}}$ & $13.2 \pm 22.2$ & $19.1 \pm 16.9$ & $<0.05$ \\
\hline
\end{tabular}

${ }^{\mathrm{a}, \mathrm{b}}$ Different superscripts in rows indicate differences significant to degree specified.

${ }^{1} P$-value is given for fat content only, because no differences occurred for thermic treatment.

especially those that had only a few phytosterol representatives (for example, $\beta$-sitosterol). Indeed, the high percentage of cholesterol was linked to type $1 \mathrm{f}$ - that is, milk rich in SFA and short-chain FA. The most probably adulterated milk was sample 14, as its FA composition, as well as its level of cholesterol, appeared quite opposite to all other samples.

We investigated several FA as potential indicators of adulteration. According to Chmilenko et al. (2011), butyric acid (C4:0) is the preferable indicator of milk naturalness. The normal level of butyric acid in standard cow milk is between 2.0 and $4.2 \%$ (GOST, 2013). In the current study, the mean butyric acid percentage in milk from group 1f was $2.13 \%$, only $0.3 \%$ in group $2 \mathrm{f}$, and not detectable in sample 14. Other FA, such as lauric (C12:0), myristic (C14:0), palmitic (C16:0), stearic $(\mathrm{C} 18: 0)$, oleic $(\mathrm{C} 18: 1)$, and linoleic acid (C18:2) have also been used as indicators of adulteration (Chmilenko et al., 2011). For all these FA, the values in 3 types were highly variable, and only samples from type 1f were in the range of the local standard defined by GOST (2013). Samples from type $2 \mathrm{f}$ had much lower values of C12:0, C14:0, and C18:0. The FA in sample 14 were almost nil (C12:0 and $\mathrm{C} 14: 0)$, very low (C16:0), or much higher than the references (C18:0 and C18:1). For example, oleic acid reached $55.2 \%$, whereas its standard range is 24 to $32 \%$.

Among the vegetable oils, tea-seed and rapeseed oils are particularly rich in oleic acid (C18:1). The percentage of oleic acid in these oils could be 60 to $80 \%$ of their fat content ( $\mathrm{Li}$ et al., 2011). In our comparative PCA, rapeseed and tea-seed profiles were effectively close to the milk samples of type $2 \mathrm{f}$, in which the oleic acid percentage was $34.2 \%$, whereas the reference values were between 24 and $32 \%$. Adulteration of those milks using vegetable oil is quite possible. Nevertheless, the proximity with other vegetable oils, such as soybean, sunflower, and corn oils, suggests that these also might be possible adulterants. Indeed, the mean linoleic acid content of type $2 \mathrm{f}$ milk (18:2) was high (5.9\%), and the latter vegetable oils are characterized by high amounts of this acid, between 40 and 65\% (Li et al., 2011). Palm oil is characterized by richness in palmitic (C16:0) and oleic acids (C18:1). This could also potentially explain the high palmitic (mean percentage of 37.2 ; normal range 22 to $33 \%$ ) and oleic acid contents of type $2 \mathrm{f}$ milk. According to Edem (2002), the adulteration of milk fat using palm oil is difficult to determine if the added quantity is low. However, Abd El-Azziz et al. (2013) quantified the changes in FA ratios according to the proportion of palm oil substituted for milk fat. They reported a decrease in butyric acid from $1.97 \%$ (pure butter oil) to $1.17 \%$ with $30 \%$ palm oil, and to $0.49 \%$ with $80 \%$ palm oil. At the same time, oleic acid increased from $27.1 \%$ to 31.0 and $36.6 \%$ with 30 and $80 \%$ added palm oil, respectively. Because, on average, our samples from type $2 \mathrm{f}$ had $0.36 \%$ butyric acid and $34.2 \%$ oleic acid, such values would correspond to almost $80 \%$ palm oil addition.

Sample 14 was characterized by its lack of butyric, lauric, and myristic acids, associated with high quantities of stearic (C18:0), oleic (C18:1), eicosanoic (C20:0), and lignoceric acids (C24:0). This pattern was relatively comparable to peanut oil, which is particularly differentiated from other vegetable oils by its high percentage of eicosanoic and lignoceric acids (Orsavova et al., 2015).

Similar observations could be made based on sterol composition. In fact, although milk samples from type 1 s did not contain phytosterols, type 2 s was characterized by large quantities of $\beta$-sitosterol and stigmasterol, found in most vegetable oils (40 to $70 \%$ for $\beta$-sitosterol; 10 to $30 \%$ for stigmasterol) except rapeseed oil (Li et al., 2011). Among type 2s, sample 3 was remarkable for its high proportion of $\beta$-sitosterol and campesterol: 53.9 and $17.3 \%$, respectively. Campesterol is contained in high quantities in most vegetable oils (more than 20\%) except sunflower and tea-seed oils (Li et al., 2011). With palm oil added at 30 and $80 \%$, as reported by Abd ElAzziz et al. (2013), cholesterol content decreased from 94.4 to $21.1 \%$, and $\beta$-sitosterol increased from 0.33 to $55.6 \%$. However, with a low proportion of added palm oil (5\%), the cholesterol ratio was maintained at a high level (more than 98\%), and only traces of phytoster- 


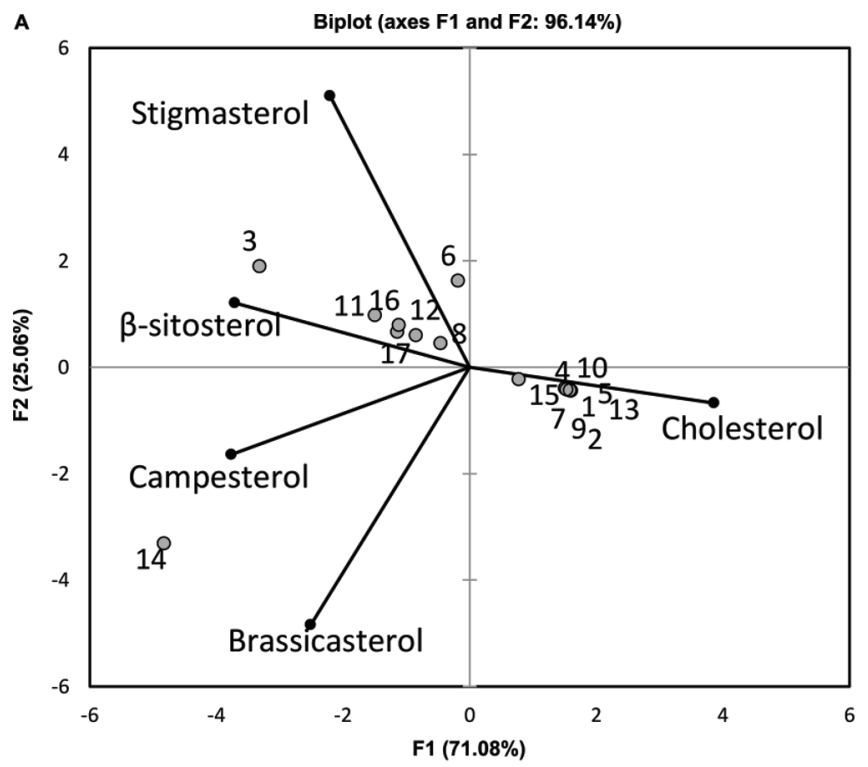

B

Observations (axes F1 and F2: $62.86 \%$ )
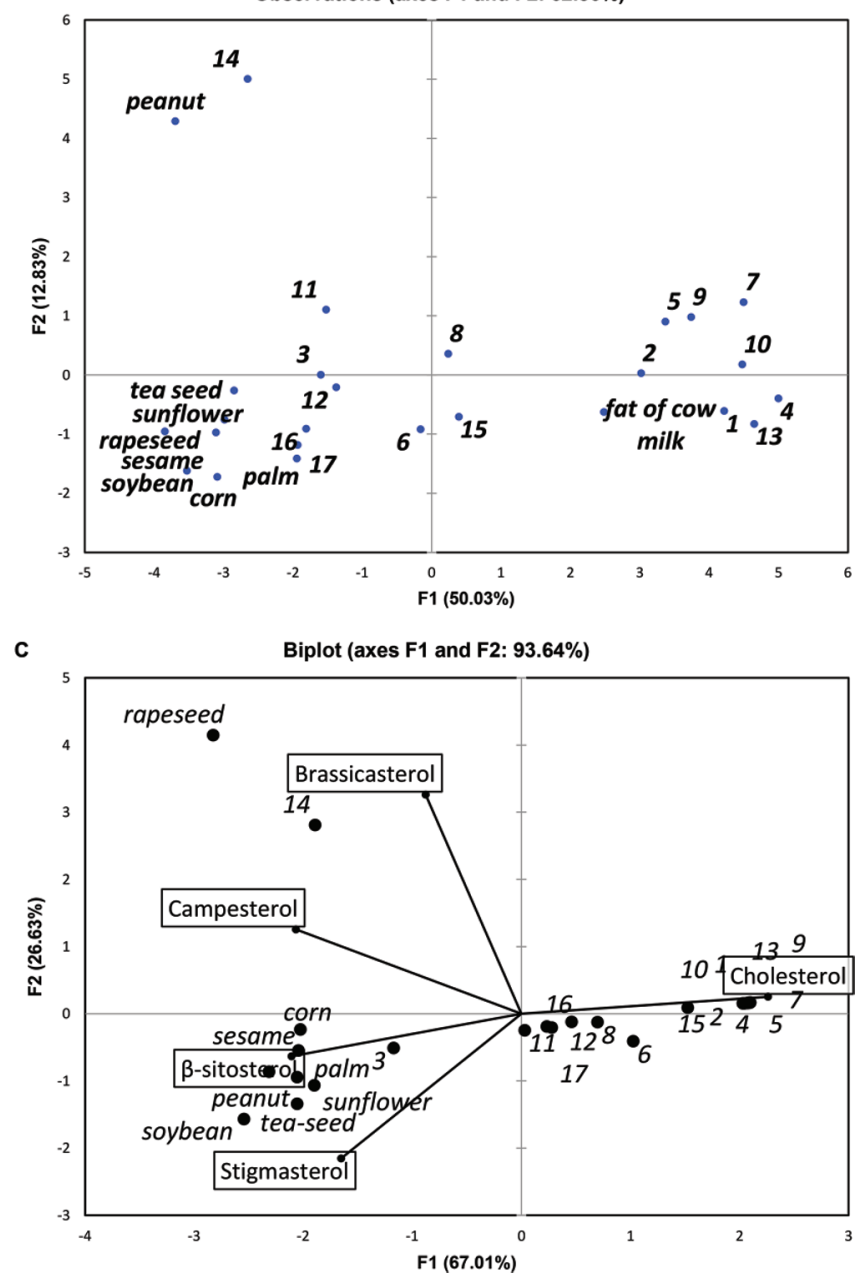

Figure 5. (A) Factorial plan (F1, F2) of the principal components analysis (PCA) applied on data table (17 milk samples $\times \%$ of sterols). Numbers correspond to the identification of milk samples. (B) Factorial plan (F1, F2) of PCA applied on data table (17 milk samples +8 vegetable oils + local fat milk $\times \%$ main fatty acid). Numbers correspond to the identification of milk samples. (C) Factorial plan (F1, F2) of PCA applied on data table $(17$ milk samples +8 vegetable oils + local fat milk $\times \%$ sterols $)$. Numbers correspond to the identification of milk samples. 


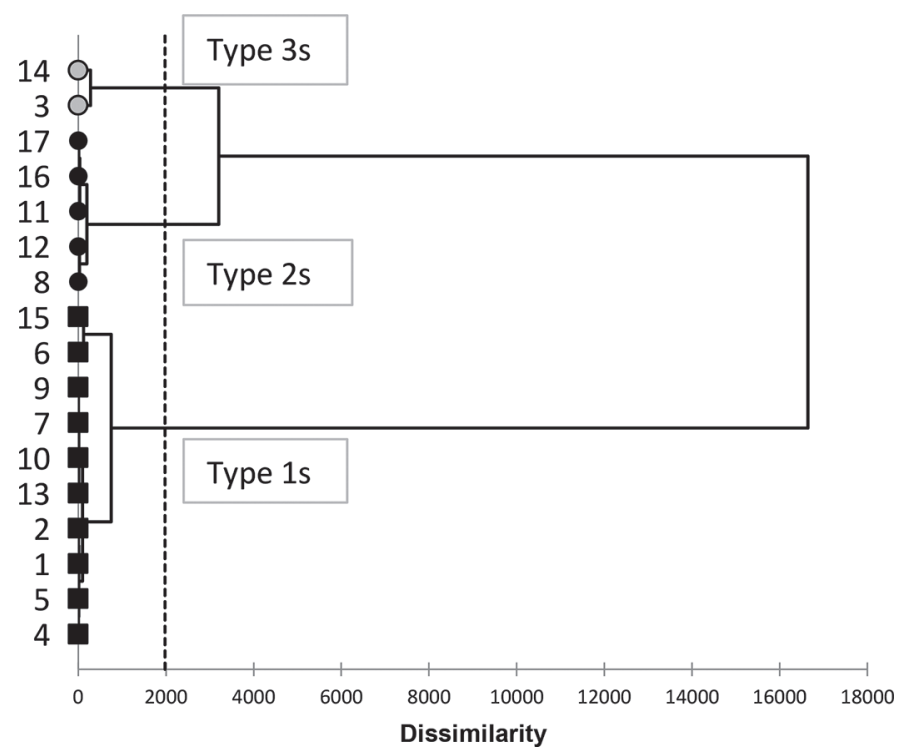

Figure 6. Classification tree and dissimilarity level of the 3 types of sterol profiles (5 sterols) of 17 milk samples derived from ascending hierarchical classification. Vertical dashed line indicates the cutting level of the dendrogram.

ols were observed (Alonso et al., 1997). In this study, similar proportions were found in sample $2(98.3 \%$ cholesterol, $0.3 \%$ campesterol, $0.2 \%$ stigmasterol, $1.2 \%$ $\beta$-sitosterol), and it was misclassified as types 1s and 1f, regarded as unadulterated.

Sample 14 was characterized by its content of brassicasterol $(5.6 \%)$, which is present in rapeseed oil only (Phillips et al., 2002). In addition, the percentage of stigmasterol in this sample was relatively low, as in rapeseed oil, which contains only approximately $1 \%$ stigmasterol (Li et al., 2011).

In our study, 2 types of milk samples were clearly identified. One was characterized by high cholesterol content (more than 98\%), which corresponds to a normal level in natural milk, and FA profiles dominated by short-chain FA and SFA. The second group included adulterated samples, recognizable by cholesterol contents below $85 \%$ and large amount of different types of phytosterols. The FA profile of this group was dominated by long-chain FA and MUFA or PUFA.

The presence of phytosterols appears quite convenient to identify adulteration of milk fat. However, such analyses must be achieved properly due to potential misidentification of $\beta$-sitosterol as lanosterol naturally present in full-fat milk (Derewiaka et al., 2011).

Globally, our samples included natural milk fat containing $100 \%$ cholesterol, milk fat with traces of phytosterols, and milk fat with high proportions of phytosterols. These 2 last groups of milk samples likely correspond to different methods of adulteration. In the first case, addition of vegetable oil could occur on the farm, at the level of production, with such milk added to pure milk from other farms, leading to dilution of the adulterated milk. In the second case, substitution of milk fat with vegetable oils might have been performed at a dairy plant during milk processing.

\section{CONCLUSIONS}

Almost $50 \%$ of the commercial milk samples available on the national market of Kazakhstan were clearly falsified. Our results support the hypothesis that the identification of adulteration in milk can be based solely on phytosterol determination: first, because the FA profiles represented exclusively the consequence of the presence or non-presence of vegetable oils used to substitute normal milk fat; second, because a slight adulteration (milk with around $98 \%$ cholesterol) did not change the FA profile significantly. The present results would encourage food authorities to reinforce the procedures of milk processing control in Kazakhstan and in the EAEU market by using phytosterol detection as a reference method proven to be reliable in national and international studies. The advantage of this method is its ability to detect slight adulteration, which could not always be detected by FA analysis. Moreover, despite the fact that milk processors are obliged to indicate the presence of vegetable oils on the milk package, consumers are not sufficiently informed in this regard. Thus, it is also necessary to develop more systematic control procedures at the national level.

\section{ACKNOWLEDGMENTS}

The present study was conducted as part of the project "Modernization of the Test Center for Qualitative and Quantitative Studies of Milk and Dairy Products, No. 037-16-GK," supported by the Foundation of Science, of the Ministry of Education and Science of the Republic of Kazakhstan.

\section{REFERENCES}

Abd El-Azziz, M., G. A. Mahran, A. A. Asker, S. S. El-Hadad, and A. F. Sayed. 2013. Comparative study between some methods for the detection of palm oil addition to milk fat. JASR 9:786-794.

Alonso, L., J. Fontecha, L. Lozada, and M. Juarez. 1997. Determination of mixtures in vegetable oils and milk fat by analysis of sterol fraction by gas chromatography. J. Am. Oil Chem. Soc. 74:131-135.

Chmilenko, F. A., N. P. Minaeva, and L. P. Sidorov. 2011. Complex chromatographic determination of the adulteration of dairy products: A new approach. Int. J. Anal. Chem. 66:572-581.

Derewiaka, D., E. Sosinska, M. Obiedzinski, A. Krogulec, and S. Czaplicki. 2011. Determination of the adulteration of butter. EJLST 113:1005-1011. 
Edem, D. O. 2002. Palm oil: Biochemical, physiological, nutritional, hematological and toxicological aspects: A review. Plant Foods Hum. Nutr. 57:319-341.

Everitt, B. S., S. Landau, and M. Leese. 2001. Cluster Analysis. 4th ed. Edward Arnold, London, UK.

Falade, A. O., G. Oboh, A. O. Ademiluyi, and O. V. Odubanjo. 2015. Consumption of thermally oxidized palm oil diets alters biochemical indices in rats. BJBAS 4:150-156.

GOST. 2013. Government standard for butter specifications. GOST 32261-2013, Appendix B1, Moscow, Russia.

GOST. 2015. Interstate standard 33490-2015: Detection of vegetable oils and plant based fat by gas-liquid chromatography with massspectrometric detection, GOST 33490-2015, 14 p.

Guan, X., and Y. Deng. 2016. Melamine-associated urinary stone. Int. J. Surg. 36:613-617.

Iwobi, A., D. Sebah, G. Spielmann, M. Maggipinto, M. Schrempp, I. Kraemer, L. Gerdes, U. Busch, and I. Huber. 2017. A multiplex real-time PCR method for the quantitative determination of equine (horse) fractions in meat products. Food Control 74:89-97.

Jolliffe, I. T. 2002. Principal Component Analysis. 2nd ed. Springer, New York, NY.

Kalamkarova, L. I., Sh. U. Zhandosov, A. V. Rokutova, A. Sh. Sharipbayeva, Yu. M. Dyu, Zh. K. Urbisinov, F. N. Bakiyev, and A. Shkodina. 2013. To the question of falsifications of milk and milk products in the Republic of Kazakhstan. (In Russian.) Medicine (Baltimore) 11:5-8.

Kazinform. 2016. Accessed Mar. 20, 2018. Fourteen dairy producers in Kazakhstan are convicted in adulteration. (In Russian.) http: //www.inform.kz/ru/14-proizvoditeley-molochnoy-produkcii-v -kazahstane-ulicheny-v-fal-sifikacii_a2915203.

Konuspayeva, G., E. Lemarie, B. Faye, G. Loiseau, and D. Montet. 2008. Fatty acid and cholesterol composition of camel's (Camelus bactrianus, Camelus dromedarius and hybrids) milk in Kazakhstan. Dairy Sci. Technol. 88:327-340.

Li, C., Y. Yao, G. Zhao, W. Cheng, H. Liu, C. Liu, Z. Shi, Y. Chen, and S. Wang. 2011. Comparison and analysis of fatty acids, sterols, and tocopherols in eight vegetable oils. J. Agric. Food Chem. 59:12493-12498.

Marrikar, J. M. N., M. E. S. Mirghani, and I. Jaswir. 2016. Application of chromatographic and infra-red spectroscopic techniques for detection of adulteration in food lipids: A review. J Food Chem. Nanotechnol. 2:32-41.

Mba, O. I., M. Dumont, and M. Ngadi. 2015. Palm oil: Processing, characterization and utilization in the food industry - A review. Food Biosci. 10:26-41.

Narmuratova, M., G. Konuspayeva, G. Loiseau, A. Serikbaeva, N. Barouh, D. Montet, and B. Faye. 2006. Fatty acids composition of dromedary and Bactrian camel milk in Kazakhstan. J. Camel Pract. Res. 13:45-50.

Nascimento, C.F., P.M. Santos, E. R. Rodrigues Pereira-Filho, and F. R. P. Rocha. 2017. Recent advances on determination of milk adulterants. Food Chem. 221:1232-1244. https://doi.org/10.1016/ j.foodchem.2016.11.034.

Ntakatsane, M. P., X. M. Liu, and P. Zhou. 2013. Short communication: Rapid detection of milk fat adulteration with vegetable oil by fluorescence spectroscopy. J. Dairy Sci. 96:2130-2136.

Orsavova, J., L. Misurcova, J. V. Ambrozova, R. Vicha, and J. Mlcek. 2015. Fatty acids composition of vegetable oils and its contribution to dietary energy intake and dependence of cardiovascular mortality on dietary intake of fatty acids. Int. J. Mol. Sci. 16:1287112890. https://doi.org/10.3390/ijms160612871.

Perotti, M. C., S. R. Rebechi, and S. M. Bernal. 2005. Detection of adulteration in fat milk by multiple linear regression analysis of fatty acid profiles. (In Spanish.) Grasas Aceites 56:67-74. https:// doi.org/10.3989/gya.2005.v56.i1.136.

Phillips, K. M., D. M. Ruggio, J. I. Toivo, M. A. Swank, and A. H. Simpkins. 2002. Free and esterified sterol composition of edible oils and fats. J. Food Compos. Anal. 15:123-142.

Tochieva, L. B. 2011. Palm oil market: 2010. (In Russian.) Accessed Mar. 6, 2018. http://id-marketing.ru/goods/rinok-palmovogo -masla-2010.htm\#start/.

Tultabayeva, T., U. Chomanov, and A. Artamonov. 2013. Study of fatty acid composition of cow milk. (In Russian.) Pages 37-41 in Proc. of the National Academy of Sciences of the Republic of Kazakhstan. Kazakh Research Institute of Processing and Food Industry LLP, Almaty, Republic of Kazakhstan.

Tultabayeva, T., U. Chomanov, B. Tultabayev, and A. Shoman. 2015. Study of fatty acids content of lipids in mare's and camel's milk. IJCEBS 3:90-93. 